\title{
Prevalence of gastrointestinal parasites in one humped camels (Camelus dromedarius) slaughtered at the Maiduguri metropolitan abattoir, Borno State, Nigeria
}

\author{
Yakaka Wakil', Jallailudeen Rabana Lawal ${ }^{1 *}$, Yagana Ahmed Gazali ${ }^{2}$, Amina Mohammed \\ Bello ${ }^{1}$, Esther Solomon Mshelia ${ }^{1}$ and Awokoya Moses Ayomikun ${ }^{1}$
}
${ }^{1}$ Department of Veterinary Medicine, Faculty of Veterinary Medicine, University of Maiduguri, P. M. B. 1069, Maiduguri, Borno State, Nigeria.
2Department of Veterinary Anatomy, Faculty of Veterinary Medicine, University of Maiduguri, P. M. B. 1069, Maiduguri, Borno State, Nigeria.

*Corresponding author. Email: rabanajallailudeen@yahoo.com. Tel: +234 8032886428.

Copyright @ 2017 Wakil et al. This article remains permanently open access under the terms of the Creative Commons Attribution License 4.0, which permits unrestricted use, distribution, and reproduction in any medium, provided the original work is properly cited.

Received 24th March, 2017; Accepted 3rd May, 2017

\begin{abstract}
This study was conducted to elucidate the prevalence of gastrointestinal parasites in one humped camels (Camelus dromedarius) slaughtered at the Maiduguri Metropolitan abattoir, Borno State, between the months of January to June 2015. Out of the 202 fecal samples collected from camels of both sexes and analyzed for the prevalence of segments, worms or oocyts of gastrointestinal parasites of camels. The overall prevalence of $69.3 \%$ was recorded, Strongyle eggs $83(41.1 \%)$ was the most dominant, followed by Strongyloides species $19(9.5 \%)$, Coccidia 15 (7.4\%), Trichuris species $9(4.5 \%)$, Ciliates 7 (3.5\%), Fasciola species $2(0.9 \%)$, Monezia species $2(0.9 \%)$, Balantidium species $1(0.5 \%)$, Amphistomes species $1(0.5 \%)$ and Ascaris $1(0.5 \%)$ respectively. Prevalent rate was higher in female 81 $(40.10 \%)$ compared to the male camels $59(29.21 \%)$. Prevalence was also found to be higher in adult $96(47.50 \%)$ compared to young camels $44(21.78)$. The occurrence of gastrointestinal parasites are more frequent in camels in slim body condition score $82(40.49 \%)$ compared to camels in good body condition $58(28.71 \%)$. It was concluded that gastrointestinal parasites of various species are still common amongst trade camels in the study area. This may constitute a major health and economic problem in the camel production in the arid and semi-arid northeastern Nigeria.
\end{abstract}

Key words: Prevalence, Gastrointestinal Parasites, one humped camels (Camelus dromedarius), Maiduguri, Northeastern Nigeria.

\section{INTRODUCTION}

The camel is an important part of the culture and agriculture of many countries and has existed as far back as the history of human civilization (Allen et al., 1992). It is an important multipurpose animal which is found in the arid and semiarid zones of the world (Al Haj and Al Kanhal, 2010). They have a unique anatomical and physiological adaptive characteristic of the harsh climatic condition of the desert areas (Rabana et al., 2011). Camels are Saharan and Sub-Saharan animals, they are also important to the people of Sahel savannah for economic and agricultural purposes (Oryan et al., 2008; Sazmand et al., 2011). Until the advent of motorized transport systems and the development of certain nomadic economics, it was referred to as the ship of the desert (Pwaveno and Arunsi, 2011). Camel meat and milk has been reported to be a source of high quality animal protein especially in areas where other animals slaughtered for meat find it difficult to thrive (FAO, 2008; Kadim et al., 2008).

The Nigerian camel population is mainly found around 
the arid zone of the country and this is shown from the slaughter figures recorded at 11,000 camels per annum in Borno State (Ghaji and Adogwa, 1986).

Camels are almost the domestic animal best adapted to the harsh environments and fluctuating nutritional conditions of the arid and extremely arid zones (Rabana et al., 2011). They are known to tolerate a lot of parasitic infections of economic importance with minimal economic losses compared to many other livestock (Radfar and Gowhari, 2013). However, camels can be infected with various gastrointestinal parasites which include nematodes cestodes, trematodes and protozoans. These are generally known to contribute to a great loss in most of animal production (Duguma et al., 2014). The major clinical signs of parasitic gastroenteritis due to internal parasitism which include; severe diarrhea, stomach pain, weight loss, reduce production rate, decrease feed intake and subsequent death in more severe cases. The zoonotic aspects of these parasites are of public health significance (Allen et al., 1992). Some of these helminth parasites also have zoonotic implication for those who work closely with camels (McCarthy and Moore, 2000; Razavi et al., 2009). This present study therefore aimed to determine the current status of the prevalence of gastrointestinal parasites in the one humped camels (Camelus dromedarius) slaughtered at Maiduguri Abattoir and to evaluate the risk factors such as age, body condition score and sex of the camels as its affects their health status and economic importance.

\section{MATERIALS AND METHOD}

\section{Study area}

This study was conducted in Maiduguri, Borno State which lies within the semi-arid zone of the Northeastern part of Nigeria, with an area of 69,436 sq.km. Maiduguri lies between Latitude $11^{\circ} \mathrm{N}$ and Longitude $13^{\circ} \mathrm{E}$. It has a mean day temperature of $38^{\circ} \mathrm{C}$.

\section{Sample population}

The camels used for this study were trade camels brought in from the neighboring countries of Chad and Niger republic and presented for slaughter at the metropolitan abattoir of which the one humped camels (Camelus dromedarius) are the most predominant, while a few two humped camels (Camelus bacterianus) are also slaughtered at the abattoir.

\section{Study design and samples size determination}

A stratified random sampling technique was adopted to determine the prevalence of gastrointestinal parasites in camels slaughtered in Maiduguri abattoir. Fecal samples were collected from the Maiduguri abattoir.

\section{Estimation of ages, body condition scoring and sexes}

Ante-mortem examination and tagging of the camels before slaughter was conducted to evaluate their ages, body condition scoring and sex. The age of the sampled camels was determined based on dentition by dental eruption according to Payne and Wilson (1999), Bello et al. (2013) and substantiated by information from Khan et al. (2003). The body condition score (BCS) of each sampled camel was evaluated by visual observation and manual palpation according to the guideline described by Faye et al. (2001). Scores of 1 to $5(1=$ very lean, $2=$ below average, $3=$ average or ideal, $4=$ above average and 5 = very fat) have been adopted to assess BCS in camels (Gaden, 2005). Notations of the fat status of spinous and transverse processes of vertebra, hollow of flank, and ribs described by Faye et al. (2001); and measurements of hump height and chest depth according to Gaden (2005) were used to score body condition. The qualitative notations described by Faye et al. (2001) were used with slight modification. For ribs, the scales were 1 = individually visible, 2 = slightly visible, $3=$ intermediate, $4=$ not very visible, and $5=$ not visible; for spinous and transverse processes of vertebrae, $1=$ very prominent, 2 $=$ prominent, 3 = intermediate, 4 = slightly prominent, and $5=$ not visible; and for hallow of flank, $1=$ very visible, 2 $=$ visible, $3=$ intermediate, $4=$ slightly visible, and $5=$ not visible. For convenience, the camels were categorized into two condition groups as "poor" (BCS of 1 to 3 ) and "good" (BCS of 4 to 5) according to Robinson (2010). Since this work was carried in the abattoir, less number of animals was found with poor BCS whereas others were within good body condition score.

\section{Sample size estimation}

The sample size was estimated based on the formula described by Thrusfield (2005) and previous prevalence of $92.4 \%$ as reported by (Pwaveno et al., 2011). But in order to increase the precision of the sampling in the study about 202 camels were considered.

\section{Fecal sample collection}

Fresh fecal samples were collected per rectum from each labeled camel using disposable hand gloves. Fecal samples were transferred into polythene bags identified, labeled and immediately transported to the University of Maiduguri, Department of Veterinary Medicine Research Laboratory for coprological analysis. Each sample was 
Table 1. Prevalence rates of the various gastrointestinal parasites in camels slaughtered at the Maiduguri abattoir.

\begin{tabular}{llcc}
\hline $\begin{array}{l}\text { Gastrointestinal } \\
\text { parasites encountered }\end{array}$ & $\begin{array}{l}\text { Species of Parasites } \\
\text { encountered }\end{array}$ & $\begin{array}{l}\text { Number of camel } \\
\text { affected (N = 202) }\end{array}$ & Prevalence (\%) \\
\hline \multirow{4}{*}{ Nematodes spp. } & Strongyles & 83 & 41.10 \\
& Strongyloides & 19 & 9.50 \\
Trichuris & 9 & 4.50 \\
Cestodes spp. & Ascaris & 1 & 0.50 \\
Trematodes spp. & Monezia & 2 & 0.90 \\
& Amphistome & 1 & 0.50 \\
Protozoan spp. & Fasciola & 2 & 0.90 \\
& Coccidia & 15 & 7.40 \\
Total & Ciliates & 7 & 3.50 \\
& Balantidium & 1 & 0.50 \\
\hline
\end{tabular}

processed using the standard floatation and sedimentation technique to identify and classify the different gastrointestinal parasites or oocyst as previously described by Hansen and Perry (1994). All parasitic eggs were identified morphologically as described by Soulsby (1992), Urquhart et al. (1996) and Brar et al. (2011).

\section{Data analysis}

The data collected were entered into Graph Pad InStat version 3.05. Descriptive statistic was used to determine the prevalence $(p)$ of the parasites and the risk factors associated with the disease (age, sex, body condition score and apparent health status). Chi-square (x2) test for their significant difference by using confidence level at $95 \%$ and $\mathrm{P}<0.05$ was considered significant.

\section{RESULTS}

Microscopic coprology revealed that some samples were positive for single and mixed infection of gastrointestinal parasite ova/oocytes. Ten (10) species of gastrointestinal parasites were recovered from the samples examined. The species include 4 species of nematodes, 1 species of cestodes, 2 species of trematodes and 3 species of protozoans. Overall prevalence rate of gastrointestinal parasites was found to be 140 (69.3\%). The various prevalent rates of gastrointestinal parasites from the infected camels revealed that Strongyle eggs 83 (41.1\%) were the most dominant followed by Strongyloides species 19 (9.5\%), Coccidia species15 (7.4\%), Trichuris species 9 (4.5\%), Ciliates 7 (3.5\%), Moneiza species 2 (0.9\%), Fasciola species 2 (0.9\%), Balantidium species 1 (0.5\%), Amphistomes species 1 (0.5\%) and Ascaris 1 $(0.5 \%)$ in descending order of occurrence in infected camels (Table 1 ).

Amongst the infected camels, females 81 (40.10\%) were more infected than the male $59(29.21 \%)$ camels. There was no significant difference $(P$-value $=0.9528$ at $95 \% \mathrm{Cl}$ ) between infection and sex of camels. Prevalent rate of gastrointestinal parasites were observed to be higher in adult camels 96 (47.52\%) compared to the young $44(21.78 \%)$. There was no significant difference $(P$-value $=0.9774$ at $95 \% \mathrm{Cl})$ between infection and ages of camels. The prevalence of gastrointestinal parasites was found to be higher in camels with poor body condition score 82 (40.59\%) compared to camels with good body condition score $58(28.71 \%)$. There was significant difference $(P$-value $=0.0300$ at $95 \% \mathrm{Cl})$ between infection and body condition score of camels (Table 2).

\section{DISCUSSION}

The present study revealed that trade camels brought for slaughtered in the study area harbors different genera of gastrointestinal parasites which include nematodes, trematodes, cestodes and protozoans which are of economic importance to the production of camels (Kamani et al., 2008). This finding is consistent with those of Bamaiyi and Kalu (2011) and Mahmuda et al. (2014) who reported the same genera of gastrointestinal parasites in camels from Maiduguri and Sokoto, Nigeria respectively. Nematodes species were the most prevalent gastrointestinal parasites in camels followed by protozoans species, followed by trematodes species and cestodes species from the study area which also agrees with the report of Mahmuda et al. (2014) and Duguma et al. (2014). The present study revealed an overall prevalent rate of $69.30 \%$ gastrointestinal parasites in the affected camels. This finding is lower than $92.4 \%$ 
Table 2. Risk factors associated with gastrointestinal parasites in trade camels in Maiduguri.

\begin{tabular}{|c|c|c|c|c|c|c|c|}
\hline Risk factors & Variables & $\begin{array}{c}\text { No. of examined } \\
\text { camels }\end{array}$ & $\begin{array}{c}\text { No. of infected } \\
\text { camels }\end{array}$ & Prevalence \% & $P$-value & $\begin{array}{c}95 \% \mathrm{Cl} \\
\mathrm{LL}-\mathrm{UL} \\
\end{array}$ & $\begin{array}{c}\text { Relative } \\
\text { Risk }\end{array}$ \\
\hline Sex & $\begin{array}{l}\text { Male } \\
\text { Female }\end{array}$ & $\begin{array}{c}87 \\
115\end{array}$ & $\begin{array}{l}59 \\
81\end{array}$ & $\begin{array}{l}29.21 \\
40.10\end{array}$ & 0.9528 & $\begin{array}{l}0.5112-0.6765 \\
0.5143-0.6561\end{array}$ & 1.016 \\
\hline Age & $\begin{array}{l}\text { Young }(<4 \\
\text { years old }) \\
\text { Adult }(>4 \\
\text { years old })\end{array}$ & 137 & 96 & $\begin{array}{l}21.78 \\
47.52\end{array}$ & 0.9774 & $\begin{array}{l}0.4978-0.6895 \\
0.5221-0.6516\end{array}$ & 1.014 \\
\hline BCS & $\begin{array}{l}\text { Good } \\
\text { Poor }\end{array}$ & $\begin{array}{c}109 \\
93\end{array}$ & $\begin{array}{l}58 \\
82\end{array}$ & $\begin{array}{l}28.71 \\
40.59\end{array}$ & $0.0300^{*}$ & $\begin{array}{l}0.5754-0.7245 \\
0.4540-0.6071\end{array}$ & 1.228 \\
\hline
\end{tabular}

${ }^{*} p<0.05, \mathbf{B C S}$, Body condition score, N, Total number of camels examined, LL - UL, Lower limit - Upper limit, Cl, Confident interval at $95 \%$.

reported in the same study area by Bamaiyi and Kalu (2011) whose study was conducted during the rainy season while the present study was carried out during the dry season. The variation in the prevalence rates may therefore be associated with the season of sample collection which is known to affect the worm burdens, abundance of parasites and its activities which are usually high during the rainy season. Considering reports from other parts of Nigeria, reports from the present finding was also lower than those reported in Sokoto with $78.0 \%$ (Mahmuda et al., 2014) and 78.5\% in Kano (Al Haj and AI Kanhai, 2010). Our finding was also lower than the 81.3\% reported in Iran (Anvari-Tafti et al., 2013), 84.80\% in Pakistan (Musadiq et al., 2013), 62.7\% in Tanzania (Swai et al., 2011) and $41.1 \%$ in Egypt (Mahmoud et al., 2008). However, our finding is higher than $68.9 \%$ reported by Kamani et al. (2008) and $37.33 \%$ by Azhar et al. (2013). The various differences from the reported prevalence rate of gastrointestinal parasites in camel from various researches may probably be associated to the different geographical locations of the study areas, time or periods of sample collection and variation in the techniques used for sample analysis or may be due to the husbandry system being employed by the camel pastoralist.

The result of the present study also concurred with the findings of $80.56 \%, 9.26 \%, 6.48 \%$ and $3.71 \%$ for nematodes, protozoans, trematodes and cestodes respectively reported by Mahmuda et al. (2014). The result of the present study revealed that Strongyle spp. eggs were found more prevalently. The high prevalence rate for strongyle spp.is consistent with previous findings of other researchers (Bamaiyi and Kalu, 2011; Mahmuda et al., 2015). This study supports previous findings that nematodes are the commonest helminths in camels (Swai et al., 2011; Duguma et al., 2014; Ibrahim et al., 2016).

The finding of the present study revealed high prevalent rate of gastrointestinal parasite infection in female camels compared to the male ones. This finding agrees with those of Bamaiyi and Kalu (2011). Demelash et al. (2014) also reported higher gastrointestinal parasite burden in female camels compared to the male ones. This could be associated with the fact that female camels' physiological peculiarities which usually constitute stress factors may be immune-suppressing which may make them to succumb to infections by the parasites than males even where both sexes share equal chances of exposure to the parasite infections (Swai et al., 2011). However, Mahmuda et al. (2014) reported a high prevalence rate of gastrointestinal parasites in male camels compared to the female ones. But the present study revealed that there was no significant difference $(P>0.05)$ in the prevalence of gastrointestinal parasite between the male and female camels.

The result of the present study also revealed high prevalent rate of gastrointestinal parasites in adult camels compared to the young ones. This finding may be associated with several exposures of adult camels to the parasites during grazing compared to the young ones. Though, there was no significant association $(P>0.05)$ between the age and occurrence of gastrointestinal parasites in the infected camels. This finding is consistent with those of Duguma et al. (2014) who reported none significant association between the prevalence of gastrointestinal parasites and the age of camels.

The present study revealed that body condition score of the camel shows significant association $(P<0.05)$ with the prevalence of gastrointestinal parasites. The presence of the association between body condition and gastrointestinal parasites agrees with previous report of Swai et al. (2011), however contrast the finding of Duguma et al. (2014) who reported the absence of association between the prevalence of gastrointestinal parasites and body condition score of camels in a similar study. This variation could probably be associated with the fact that loss of body condition in the camels could be due to other factors such as seasonal changes and the presence of other concurrent disease conditions which may suppress the immune system and make the camel 
vulnerable to parasitic diseases.

\section{Conclusion}

In conclusion, gastrointestinal parasites of various species are prevalent amongst one humped camel in Maiduguri, the occurrence was found to be more in female and adult camels. Therefore, there is need for strategic deworming of camel using broad spectrum anthelmintic, coupled with good management practice for enhancing the productivity of camels as well as other livestock reared in close proximity.

\section{CONFLICT OF INTEREST}

The authors have not declared any conflict of interest.

\section{ACKNOWLEDGEMENT}

The authors wish to thank the technical staff of the Postgraduate Research Laboratory, Department of Veterinary Medicine, University of Maiduguri for their support and technical guidance.

\section{REFERENCES}

Al haj, O. A., \& Al Kanhal, H. A. (2010). Compositional, technological and nutritional aspects of dromedary camel milk. International Dairy Journal, 20(12), 811-821.

Allen, A. F., \& Salman, R. (1992). The camel conference production.1st International Edition. Pp. 85- 87.

Anvari-Tafti. M., Sazmand, A., Hekmatimoghaddam, S., \& Moobedi, I. (2013). Gastrointestinal helminthes of camels (Camelus dromedarius) in center of Iran. Tropical Biomedicine, 30(1), 56-61

Azhar, M., Lateef, M., \& Zahid, M. I. (2013). Prevalence and Chemotherapy of Gastrointestinal Parasites of Camels. International Camel Conference, p. 44.

Bamaiyi, P. H.. \& Kalu, A. U. (2011). Gastrointestinal parasites infection in one humped camels (Camelus dromedarius) of Nigeria. Veterinary Research Forum. 2(4), 278-281.

Bello, A., Sonfada, M. L., Umar, A. A., Umaru, M. A., Shehu, S. A., Hena, S. A., Onu, J. E., \& Fatima, O. O. (2013). Age estimation of camel in Nigeria using rostral dentition. Sci. J.of Anim. Sci., 2(1), 9-14.

Brar, R. S., Sandhu, H. S., \& Singh, A. (2011). Veterinary Clinical Diagnosis by Laboratory methods. First Edition. India, Kalyani Publishers., 28, 216-217.

Demelash, K., Alemu, F., Niguse, A., \& Feyera, T. (2014). Prevalence of Gastrointestinal Parasites and Efficacy of Anthelmintics against Nematodes in Camels in Yabello District, Southern Ethiopia. Acta Parasitologica Globalis, 5(3), 223-231.

Duguma, A. Eshetu, E., \& Gelan, E. (2014). Preliminary study on the prevalence and risk factors associated with gastrointestinal parasites of Camels in Yabello district,
Southern rangeland of Ethiopia. African Journal of Agricultural Research, 9(43), 3191-3196.

FAO (2008). Camel Milk. In: Animal Production and Health Division, Food and Agriculture Organization of the United Nations.

Faye, B., Bengoumi, M., Cleradin, A., Tabarani, A., Chilliard, Y. (2001). Body condition score in dromedary camel: a tool for management of reproduction. Emir. J. Agic. Sci.; 13, 01-06.

Gaden B., (2005). Identifying live animal condition scoring systems for the Australian livestock export industry. Meat and Livestock Australia, North Sydney, Australia, p. 93.

Ghaji, A., \& Adogwa, A. O. (1986). The significance of Camel production in Nigeria. Nigerian J. Anim. Prod., 13, 29-35.

Hansen, J., \& Perry, B. (1994). The Epidemiology, Diagnosis and Control of Helminth Parasites of Ruminants. A Hand Book, Food and Agricultural Organization of the United Nations, Rome, Italy, Pp. 72-89.

Ibrahim, M., Ahmed, A. H., Kadle, A. A., \& Yusuf, H. (2016). Gastro-Intestinal Parasites of Camels (Camelus dromedarius) from Mogadishu, Somalia. Open Journal of Veterinary Medicine, 6, 112-118.

Kadim, I. T., Mahgoub, O., \& Purchas, R.W. A. (2008). Review of the growth and of the carcass and meat quality characteristics of the one-humped camel (Camelus dromedarius). Meat Sci., 80(3), 555-569.

Kamani. J., Turaki, A. U., Egwu, G. O, Mani, A. U., Kida, S. M., Abdullahi, J. G., Damina, M. S., Kumshe, H. A., \& Dogo, G. I. (2008). Prevalence of gastrointestinal parasites in camels (Camelus dromedarius) slaughtered in Maiduguri, Nigeria. Journal of Camel Practice and Research, 15(2), 181-182.

Mahmoud, M. A., Amin, M. M., Youssef, R. R., El-Kattan, A., Goda, A. S .A., \& AbouEl-Naga, T. R. (2008). Studies on Some Endoparasites of Camels in the Southeastern Area of Egypt. SCVMJ, XIII, 81-92.

Mahmuda, A., Mohammed, A. A., Alayande, M. O., Habila, Y. I., Lawal, M. D., Usman, M., Raji, A. A., Saidu, B., Yahaya, M. S., \& Suleiman, N. (2014). Prevalence and distribution of gastrointestinal parasites of working camels in Sokoto metropolis. Veterinary World, 7(3), 108-112.

McCarthy, J., \& Moore, T. A. (2000). Emerging helminthes zoonoses. Inter. J. Parasitol., 30(12-13), 1351-1359.

Musadiq, I., Malik, J., Ahmad, F., Mehmood, K., Rehman, T., Samad, H. A., Riaz, M. T., \& Sattar, K. (2013). An Epidemiological Survey of Gastrointestinal Parasites of Camels in Cholistan Desert. International Camel Conference, p. 35.

Oryan, A., Valinezhad, A., \& Bahrami, S. (2008). Prevalence and pathology of camel filariasis in Iran. Parasitology Research, 103, 1125-1131.

Payne, W. J. A. and Wilson R. T. (1999). An introduction to animal husbandry in the tropics. Blackwell Science Ltd., UK, pp. 1306.

Pwaveno, H. B., \& Arunsi, U. K. (2011). Gastrointestinal parasite infections in one humped camel (Camelus dromedarius) of Nigeria. Vet Res Forum, 2(4), 278-881.

Rabana, J. L., Kumshe, H. A., Kamani, J., Grema H., Turaki, U. A., \& Harrison, K. D. (2011). Effects of Parasitic Infections on Erythrocyte Indices of Camels in Nigeria. Veterinary Research forum, 2(1), 59-63.

Radfar, M. H., \& Gowhari, M. A. (2013). Common gastrointestinal parasites of indigenous camels (Camelus dromedarius) with traditional husbandry management (freeranging system) in central deserts of Iran. J. Parasit. Dis., 
37(2), 225-230.

Razavi, M., Oryan A., Bahrami S., Mohammadalipour A. and Gowhari, M. (2009). Prevalence of Cryptosporidium infection in camels (Camelus dromedarius) in a slaughter house in Iran. Tropical Biomedicine, 26 (3): 267-273.

Robinson, I. (2010). PET-livestock Somalia: apictorial evaluation tool (PET) for livestock condition scoring in Somalia. AA International Ltd., Aberystwyth, Wales, UK, p. 62.

Sazmand, A., Rasooli, A., Nouri, M., Hamidinejat, H., \& Hekmatimoghaddam, S. (2011). Serobiochemical alterations in subclinically affected dromedary camels with Trypanosoma evansi in Iran. Pakistan Veterinary Journal, 31, 223-226.

Soulsby, E. J. L. (1992). Helminthes, Arthropods and protozoa parasites of domesticated animals, Bailere Tindal, London, Pp. 232-233.
Swai, E. S., Moshy, W., Mshanga, D., Lutatina, J., \& Bwanga, S. (2011). Intestinal Parasitic Infections of Camels in the Agro and Pastoral Areas of Northern Tanzania. Veterinary Research, 4, 34-38.

Thrusfield, M. (2005). Veterinary Epidemiology. London: Blackwell Science Ltd. Pp. 228-246.

Urquhart, G. M., Armour, J., Duncan, J. L., Dunn, A. M., \& Jennings, F. W. (1996). Veterinary Parasitology. Second Edition. Oxford UK, Blackwell Science Ltd., London. Pp. 1133. 